\title{
Brasília: tombar x tombar
}

\section{Brasília: tipping $x$ tipping}

Natalha de Faria Costa' Regina de Souza Maniçoba ${ }^{2}$
Data de submissão: 22-07-2014

Data de aprovação: 22-08-2014

1 Licenciada em Geografia - UPIS. Bacharel em Geografia - UniCEUB. natalhafc@gmail.com.

2 Professora de Geografia do UniCEUB. Mestre em Gestão Urbana e Regional pela Universidade de Brasília - UnB. Doutora em Desenvolvimento Sustentável pela Universidade de Brasília.regina.manicoba@uniceub.br.

\section{Resumo}

A preocupação em preservar o patrimônio cultural e histórico mundial se torna cada vez mais necessária, haja vista as mudanças no espaço urbano que podem ocasionar a descaracterização das heranças arquitetônicas de muitas cidades. No presente artigo, será analisado o estudo de caso da cidade de Brasília, cujo tombamento se deu por esta ser uma cidade moderna, concepção urbana estaque não ocorre em outras cidades brasileiras, sendo este, um ponto único para preservação. Para isso, foi realizada pesquisa bibliográfica em livros e periódicos, sobre a concepção e tombamento de Brasília. Foram utilizados os relatórios da UNESCO, o documento Brasília Revisitada de Lúcio Costa, além de dados gerais fornecidos pela Secretaria de Habitação do Distrito Federal e Secretaria da Cultura. Ao se analisar a formação espacial da cidade atualmente pode-se perceber a desfiguração de diversos pontos do projeto original, que deveriam ter sido geridos de forma diferente visando a sua preservação. O relatório da UNESCO, de 2012, apontou os pontos críticos para preservar em Brasília, que são definidas como áreas prioritárias de intervenção, como sendo as margens do Lago Paranoá e a Avenida W3.

Palavras-chave: Brasília. Patrimônio. Tombamento. UNESCO.

\section{Abstract}

The concern to preserve the cultural heritage and historical world becomes increasingly necessary considering the changes brought about in space, especially in urban areas that can cause the extinction of these heritages. The case in study, the city of Brasilia, the tipping took the unique design of the capital, a modern city. The urban design of the same does not occur in other locations, being a single point for preservation. For this, literature search was conducted in books and periodicals, on the design and tipping of Brasilia. Reports, the UNESCO document Brasilia Revisited Lucio Costa, and general data supplied by the Secretary of Housing and Federal District Department of Culture were used too. When analyzing the spatial formation of the city can currently be seen defacing several points that should have been managed differently in order to be preserved at the same time the offer of basic services to the population. The critical points to preserve in Brasilia are covered mainly by UNESCO report in 2012, which defined the priority areas for intervention as the shore of Lake Paranoá and the Avenue W3.

Keywords: Brasília. Heritage.Tipping. UNESCO. 


\section{Introdução}

A necessidade de preservar a história e a cultura para as gerações futuras tem sido garantida graças a iniciativas como a da Organização das Nações Unidas para a Educação, a Ciência e a Cultura (UNESCO) $)^{3}$, que acolhe as indicações dos Estados-membro sobre áreas, sítios e/ ou edifícios para serem incorporados a sua Lista do Patrimônio Mundial, que visa valorizar e proteger obras de imenso valor para a cultura da humanidade.

No Brasil há diversos dispositivos legais que auxiliam a preservação e manutenção do patrimônio; desde leis e institutos federais, municipais à própria Constituição brasileira, que versa sobre os direitos e deveres que todos os cidadãos têm com relação à preservação e manifestação da sua cultura.

Dentre as várias localidades tombadas no Brasil, está a própria capital federal, Brasília, que por seu projeto de cidade moderna, foi incluída como patrimônio cultural da humanidade pela UNESCO em 1987, sendo uma cidade com padrões arquitetônicos que não se repetem em outros locais do mundo.

Porém, como em todas as cidades, problemas relacionados, principalmente, ao planejamento e gestão urbana têm descaracterizado o plano inicial de Brasília, sendo comum processo de ocupação na orla do Lago Paranoá, o desrespeito ao gabarito das edificações, a invasão de áreas públicas nas Asas Sul e Norte, expansão urbana desordenada, dentre outros. A preocupação do governo brasileiro e da UNESCO é que, em um futuro próximo, os traços únicos de Brasília sejam perdidos. O Decreto $\mathrm{n}^{\circ}$ 10.829, de outubro de 1987, que se refere à preservação da concepção urbanística de Brasília então é rígido em diversos pontos, visando impedir mudanças que possam descaracterizar esta área.

Essa rigidez no tombamento, que veta transformações na cidade, tem sido criticada por autores como James Holston (1993), que argumenta ser preciso preservar o "espírito de invenção" de Brasília ou pelo próprio Oscar Niemeyer (apud MENCHEN, 2009), que se refere ao tombamento de Brasília como "uma besteira", porque as modificações nas cidades são inevitáveis, "o tempo

3 A UNESCO atua em parceria com as três esferas de governo: federal, estadual e municipal e com a sociedade civil. O Centro do Patrimônio Mundial é o ponto focal e coordenador, dentro da UNESCO, de todos os assuntos relativos ao Patrimônio Mundial. obriga a isso".

Para análise das modificações do espaço brasiliense foi realizada pesquisa bibliográfica por meio de livros e periódicos, sobre a concepção e tombamento de Brasília. No que diz respeito ao tombamento, foram utilizados os relatórios da UNESCO, o documento Brasília Revisitada de Lúcio Costa e entrevistas de periódicos com o arquiteto Oscar Niemeyer, além de dados gerais fornecidos pela Secretaria de Habitação do Distrito Federal e Secretaria da Cultura.

Traçando-se um paralelo entre a preservação e o desenvolvimento, o objetivo deste trabalho é analisar as principais modificações espaciais ocorridas em Brasília, em desacordo com o seu projeto inicial, para identificar quais são os pontos críticos que merecem a atenção imediata do governo, seja para melhoria dos serviços básicos demandados pelo povo ou para resguardar a história do país.

\section{Patrimônio cultural e tombamento: a impor- tância da preservação}

A humanidade por milhares de anos tem criado obras de imenso valor histórico e cultural, sejam elas físicas ou não. Diante disso, a necessidade de preservar as características de cada povo é fundamental para que no futuro possamos compreender a nossa história e como se deu a formação do espaço atual.

Conforme mencionado pelo UNESCO (2013b), entende-se por patrimônio cultural mundial "a composição de monumentos, edifícios ou sítios que tenham um excepcional e universal valor histórico, estético, arqueológico, científico, etnológico ou antropológico".

A Constituição Federal Brasileira, no seu artigo 215, define como um dos direitos básicos para qualquer cidadão brasileiro o princípio de cidadania cultural: "O Estado garantirá a todos o pleno exercício dos direitos culturais e acesso às fontes da cultura nacional, e apoiará e incentivará a valorização e difusão das manifestações culturais" (BRASIL, 1988). Percebe-se, portanto a preocupação fixada na constituição com a cultura, fazendo com que os governos, os demais agentes sociais e as instituições privadas devam prezar pela conservação dos principais aspectos culturais de uma população.

A gestão das áreas a serem preservadas é majoritariamente dos Estados-parte, como previsto no art. 4 da Convenção para a Proteção do Patrimônio Mundial, Cultural e Natural (UNESCO, 1972). Sendo assim, o go- 
verno brasileiro, como um dos Estados-Membros, deve tomar as medidas cabíveis e, caso necessário, pedir ajuda internacional.

$\mathrm{O}$ art. 5 da mesma Convenção da UNESCO ressalta que estes Estados-parte também precisam: "adotar uma política geral com vistas a atribuir função ao patrimônio cultural e natural na vida coletiva e a integrar sua proteção aos programas de planejamento" (UNESCO, 1972). Partindo deste princípio, cabe também ao poder público o planejamento da localidade para melhor beneficiar a população local, principalmente quanto àqueles patrimônios estão presentes em áreas urbanas.

Nesse sentido, para preservar as áreas de grande valor histórico, estético, arqueológico, científico, etnológico ou antropológico, os governos realizam o tombamento, que conforme a Secretaria de Estado da Cultura do Paraná (2013) é "um ato administrativo, realizado pelo poder público, por meio de legislação específica, com objetivo de impedir que o patrimônio venha a ser descaracterizado ou destruído". Por meio do tombamento, busca-se a preservação e fiscalização, qualquer modificação na área tombada devendo ser previamente autorizada pelo órgão competente.

Conforme o IPHAN (2014), "os tombamentos federais são responsabilidade do IPHAN e começam pelo pedido de abertura do processo, por iniciativa de qualquer cidadão ou instituição pública" e visam preservar bens de valor histórico, cultural, arquitetônico, ambiental e também de valor afetivo para a população, impedindo a destruição e/ou descaracterização destes.

Conforme apontado pela UNESCO (2013a), os sítios do Patrimônio Mundial pertencem a todos os povos, não importando o território em que estejam localizados, também há a necessidade de se preservar levando em conta a comunidade internacional, por isso a gestão de cidades como Brasília, símbolo da Arquitetura Moderna, deve ser feita com cuidado para que não se percam os traços originalmente tombados.

Nesse sentido, modificações em sua área, por exemplo, só podem ser feitas com a autorização do órgão competente, Instituto do Patrimônio Histórico e Artístico Nacional (IPHAN), no caso de Brasília, sendo que muitas obras que poderiam beneficiar ou prejudicar de alguma forma a população local e os bens tombados ou seu entorno não são autorizadas pelos possíveis impactos a serem gerados.

Para o Brasil como um todo, a organização e proteção do patrimônio histórico e artístico estão definidos no Decreto-Lei $\mathrm{n}^{\circ} 25$, de 30 de novembro de 1937. Neste, o governo define que o interesse em se preservar deve ser: "[...] quer por sua vinculação a fatos memoráveis da história do Brasil, quer por seu excepcional valor arqueológico ou etnográfico, bibliográfico ou artístico" (BRASIL, 1937).

Basicamente, o objetivo principal de todas as legislações relacionadas à proteção de patrimônio é registrar a história do País para as futuras gerações. Mas, a forma como isso deve e tem sido feito, requer severos cuidados.

Além das leis federais que regem a política de tombamento no Brasil, cada estado e município têm certa autonomia para regular os seus dispositivos, sendo os órgãos federais responsáveis: o Instituto do Patrimônio Histórico e Artístico Nacional (IPHAN); nos estados federados, o Instituto Estadual do Patrimônio Histórico e Artístico (IEPHA); e, nos municípios, as secretarias municipais de cultura (BORGES, 2005).

Ao se analisar diversos pontos tombados pela UNESCO no território brasileiro ${ }^{4}$, pode-se perceber o quanto a preservação destes é importante, já que essas obras possuem significados únicos. No entanto, deve-se observar também as necessidades dos moradores atuais, que podem ter urgência por obras consideradas básicas (como a construção de passarelas no Eixão ou de estacionamentos próximos às áreas comerciais), como no caso da cidade de Brasília.

Brasília foi inscrita como um patrimônio Cultural Mundial em 7 de dezembro do ano de 1987, sendo a cidade com maior área tombada do mundo $\left(112,25 \mathrm{~km}^{2}\right)$, como afirma a SEPLAN (2014). Além disto, leva o título de único conjunto urbanístico contemporâneo moderno. Considerando-se essas características, é possível perceber as especificidades da cidade e a sua necessidade de preservação, visto que não existem muitos outros exemplos iguais espalhados pelo mundo (SEDHAB, 2012).

4 Conforme IPHAN (2014) são considerados Patrimônio Mundial: "Cidade Histórica de Ouro Preto; Centro Histórico de Olinda; Missões Jesuítas Guaranis - no Brasil; ruínas de São Miguel das Missões; Santuário de Bom Jesus de Matosinhos - Congonhas; Centro Histórico Salvador, Bahia; Brasília, Distrito Federal; Parque Nacional Serra da Capivara; Centro Histórico de São Luís; Centro Histórico de Diamantina; Pantanal Mato-grossense; Rio de Janeiro, paisagens cariocas entre a montanha e o mar; Parque Nacional do Jaú; Costa do Descobrimento; Reserva Mata Atlântica; Cidade de Goiás; Ilhas Atlânticas; Praça São Francisco na cidade de São Cristóvão". 


\section{A cidade moderna: Brasília}

O Distrito Federal é uma área de $5.771 \mathrm{~km} 2$ demarcada nas proximidades do centro do Planalto Central. Em seu redor, há cerca de 2 milhões de $\mathrm{km}^{2}$ de cerrado, estendendo-se sem variação significante, entre 1.000 e $1.300 \mathrm{~m}$ acima do nível do mar. Esse vasto platô representa $23 \%$ da área do país e, em 1980, abrigava apenas 6\% de sua população concentrada, sobretudo em cidades e postos agrícolas avançados das zonas pioneiras (HOLSTON, 1993).

Brasília surge com a intenção de capital do país e integração nacional. Desde o último quartel do século XVIII, reformadores, revolucionários e estadistas propunham a transferência da capital para o interior como meio de povoar, desenvolver e assegurar a posse do vasto sertão brasileiro (HOLSTON, 1993).

Conforme cita Cataldo e Ramos (2010), existente desde a época da sua construção, o objetivo de interiorizar o desenvolvimento se concretizou como pode ser visualizado pela força econômica do Centro-Oeste do país. A construção da Nova Capital assim, mudou o mapa político do Brasil fazendo emergir uma potência econômica no Planalto Central.

Sua localização foi prevista no sonho de D. Bosco e decidida com base nos estudos de campo realizados pela Missão Cruls (realizada em 1892), em que critérios foram estabelecidos para sua ideal localização, como: intensificação das transações econômicas internas entre as diferentes regiões centralizadas pela capital a ser construída; localização favorável a segurança nacional, evitando invasões estrangeiras; área que possuísse ar saudável e estivesse próxima de fontes hídricas (ARAGÃO, 2011).

A profecia de João Melchior Bosco (conhecido como Dom Bosco) é um, dentre os vários mitos de fundação, oficialmente reconhecidos nos monumentos e nos livros de história da cidade. Esses mitos são versões diversas do mesmo tema: apresentam Brasília como agente civilizador do Planalto Central, como prenunciadora de um desenvolvimento invertido no qual a capital criaria a civilização sobre a qual exerceria uma radiosa soberania (HOLSTON, 1993).

Essa ideia adquiriu forma legal na primeira Constituição republicana de 1891 . Em seu artigo terceiro esta reservou uma área de $14.400 \mathrm{~km}^{2}$ no Planalto Central para a instalação da futura capital federal.

Art $3^{\circ}-$ Fica pertencendo à União, no planalto central da República, uma zona de 14.400 quilômetros quadrados, que será oportunamente demarcada para nela estabelecer-se a futura Capital federal.

Parágrafo único - efetuada a mudança da Capital, o atual Distrito Federal passará a constituir um Estado (BRASIL, 1891).

Porém, apenas em 1955, a ideia de construir Brasília foi à frente durante a campanha presidencial de Juscelino Kubitschek (JK), que assumiu o compromisso de construir a nova capital, tornando esta, a principal meta de sua administração (1956-1960), a dita "Meta-Síntese”.

Kubitschek deu a Brasília prioridade máxima. Para ele, a construção da capital daria origem tanto à integração nacional como ao desenvolvimento regional, levando o mercado nacional às regiões de economia apenas de subsistência. Além disso, Brasília iria produzir tanto um novo espaço nacional quanto uma nova época para o país, incorporando o interior à economia e, sendo ao mesmo tempo, o marco decisivo na trajetória temporal deste rumo à sua emergência como uma grande nação.

Até a construção da Nova Capital no Planalto Central, havia um muro entre a escassez do interior e a abundância do litoral, sem estradas a ligar os dois pontos. Atualmente, as diferenças entre as regiões ainda existem e são muitas, mas JK deflagrou um processo que representou "o redescobrimento do Brasil" (VEJA, 2013).

Como cita Tavares (2010a), a intenção inicial de JK era atribuir a Oscar Niemeyer o planejamento de toda a cidade, mas este, entretanto, não aceitou a incumbência (ficando responsável apenas pelo projeto dos principais edifícios da cidade), e sugeriu que se fizesse um concurso para a escolha do projeto urbano.

Para iniciar as obras, o Governo Federal realizou então um concurso (o Concurso Nacional do Plano Piloto da Nova Capital do Brasil, edital, aprovado em 24 de setembro de 1956) para escolha do projeto urbanístico de Brasília. Este solicitava ideias de design e não detalhes organizacionais, enfatizando a forma mais apropriada para exprimir o caráter fundamental da cidade enquanto capital do Brasil, exprimindo assim, a grandeza da vontade nacional (VEJA, 2013).

Em 1957, o plano de Lúcio Costa, é escolhido como vencedor deste concurso (Figura 1). Tal plano não trazia nenhuma linha de desenho técnico, nenhuma maquete, estudos de uso da terra, mapas demográficos ou esquemas para desenvolvimento econômico ou organização administrativa. Em suma, reduzia-se em nada mais que a ideia de uma capital (HOLSTON, 1993). "Nasceu 
do gesto primário de quem assinala um lugar ou dele toma posse - dois eixos cruzando-se em ângulo reto, ou seja, o próprio sinal da cruz" (COSTA, 1987, p. 36).

Figura 1 - Projeto Plano Piloto de Lúcio Costa

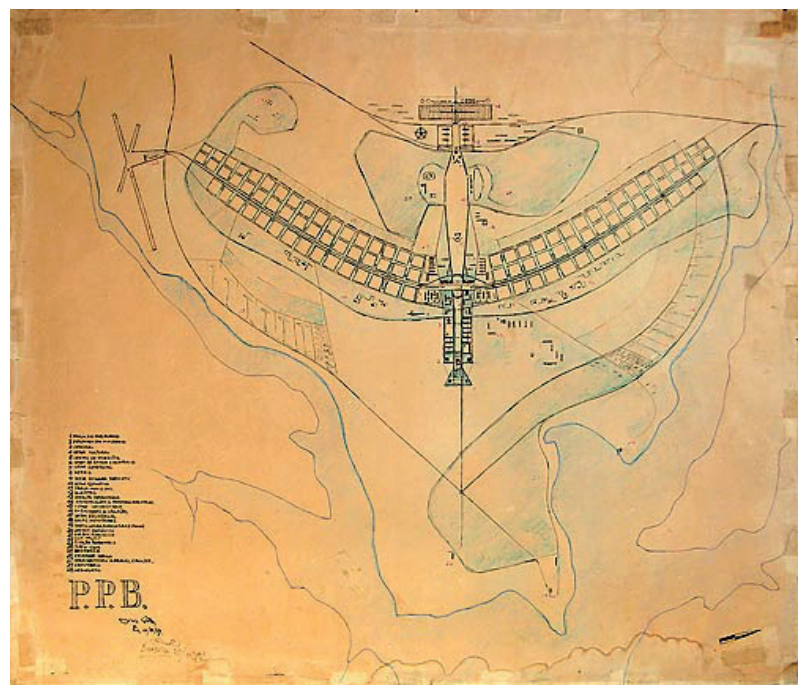

Fonte: VEJA (2013).

De acordo com Lúcio Costa, o plano consistia em três elementos estruturais básicos: o cruzamento de dois eixos, dois terraplanos e uma plataforma (COSTA, 1987). Plano Piloto é o termo utilizado para designar tanto o projeto de Lúcio Costa quanto, posteriormente, a cidade propriamente dita.

Conforme a Ata do Concurso, Plano Piloto da Nova Capital (apud TAVARES, 2010b), de 1957, para os membros do júri, o projeto que melhor integrava os elementos monumentais na vida quotidiana da cidade, como Capital Federal, apresentado numa composição coerente, racional, de essência urbana - uma obra de arte era o de Lúcio Costa.

De acordo com Tavares (2010a), a maior contribuição do projeto de Lúcio Costa está no conjunto de superquadras que, segundo ele, "trazem inovações quanto ao adensamento e concepção de escala, ao uso e ocupação do solo, à relação entre espaço público e privado, à composição arquitetônica e a de gabaritos".

\section{A proporcionalidade desenhando a cidade}

Datado de 14 de outubro de 1987, o Decreto ${ }^{\circ}$ 10.829, define a preservação urbanística de Brasília. Nesse decreto, são apontadas como áreas a serem preservadas aquelas originalmente projetadas pelo arquiteto Lúcio Costa, sendo a área considerada como Plano Piloto: “[...] delimitada a Leste pela orla do Lago Paranoá, a Oeste pela Estrada Parque Indústria e Abastecimento (EPIA), ao Sul pelo Córrego Vicente Pires e ao Norte pelo Córrego Bananal" (BRASIL, 1987). A figura 1 mostra a área inicial do Plano Piloto.

Além desse decreto, também existem outras duas instâncias que protegem o patrimônio de Brasília: a resolução da UNESCO, que o incluiu na Lista de Patrimônio Mundial, em 11 de dezembro de 1987 e o tombamento federal instituído em 14 de março de 1990. A candidatura de Brasília para a lista de Patrimônio da humanidade teve início com uma carta de Lúcio Costa à Ítalo Campofiorito que havia assumido na época a direção do Patrimônio Histórico e Artístico Nacional (PESSÔA, s.d.).

Posteriormente, também foram incluídas as seguintes regiões administrativas como áreas tombadas: Candangolândia, Cruzeiro e Sudoeste/Áreas Octogonais (Figura 2).

Figura 2 - Conjunto urbanístico tombado de Brasília

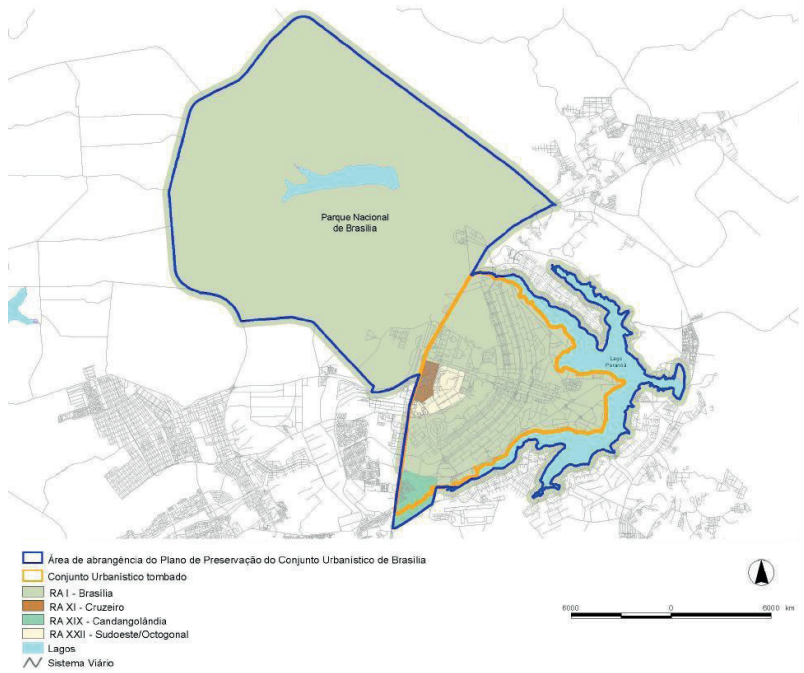

Fonte: Prefeitura da HIGS 706 (2010).

A preservação da concepção urbanística de Brasília foi dividida em quatro escalas, conforme o projeto de Lúcio Costa, mas tendo como base as chaves de planejamento urbano definidas por Le Corbusier (1957) que são: moradia, trabalho, lazer (nas horas livres) e circulação (HOLSTON, 1993).

O Plano de Brasília é uma ilustração perfeita do zoneamento dessas funções em uma cidade. Um cruzamento de vias expressas determina a organização e a forma da cidade: "corredor de norte a sul, e de leste a oeste, formando os dois grandes eixos da cidade, haverá grandes artérias para o tráfego de alta velocidade em uma única direção" (HOSTON, 1993, p. 38). Superquadras residenciais são colocadas ao longo de um dos eixos, áreas 
de trabalho ao longo do outro. O centro público se localiza num lado do cruzamento entre os dois eixos. A área de recreação toma a forma de um lago e um cinturão verde rodeia a cidade (HOLSTON, 1993).

A concepção urbana de Brasília se traduz em quatro escalas distintas: a monumental, a residencial, a gregária e a bucólica (Figura 3).

Figura 3 - Mapa das escalas predominantes

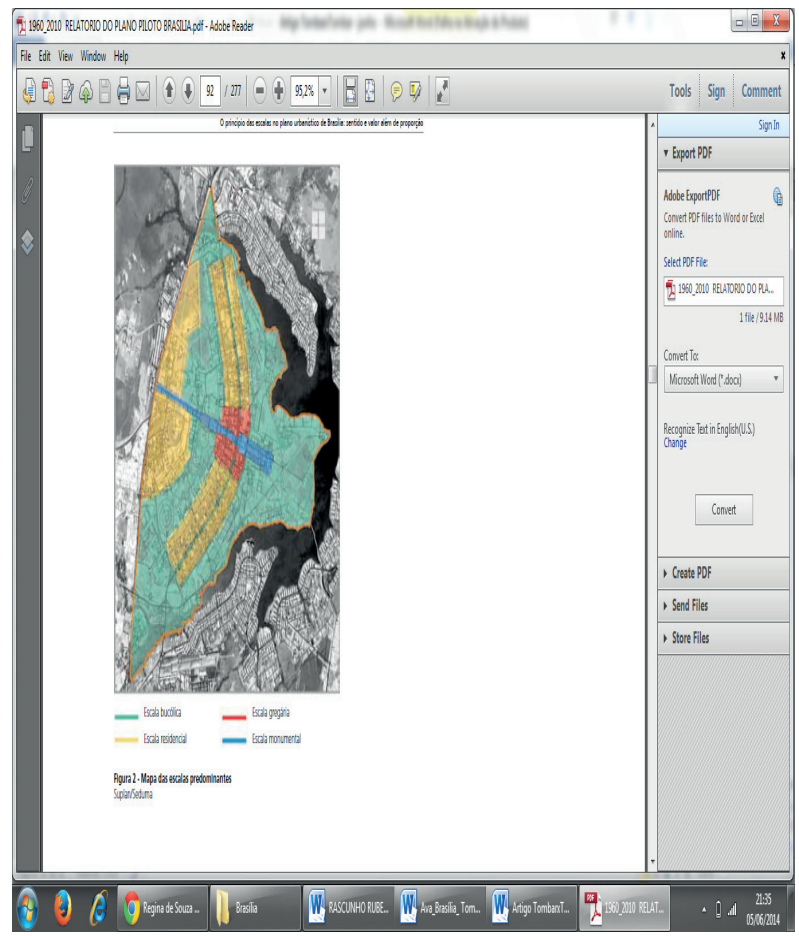

Fonte: Suplan/Seduma (apud LEITÃO, 2009, p. 90).

A presença da escala monumental "não no sentido da ostentação, mas no sentido da expressão palpável, por assim dizer, consciente daquilo que vale e significa" (COSTA, 1987, p.116), conferiu à cidade, desde seus primórdios, as características de efetiva capital do país. Lúcio Costa em carta a Ítalo Campofioritto (apud LEITÃO, 2009, p. 89), em1990, ressalta essa escala que:

[...] comanda o eixo retilíneo - Eixo Monumental - desde a Praça dos Três Poderes até a Praça do Buriti e foi introduzida através da aplicação da técnica milenar dos terraplenos (Praça dos Três Poderes, Esplanada dos Ministérios), da disposição disciplinada, porém rica, das massas edificadas, das referências verticais do Congresso Nacional e da Torre de Televisão e do canteiro central gramado e livre de ocupação, como se Brasília fosse atravessada, do nascente ao poente, por uma fatia de céu que viesse até o chão.

A escala residencial é representada pela proposta inovadora da Superquadra, onde destaca-se como características que a diferenciam: "o gabarito uniforme de seis pavimentos, o chão livre e acessível a todos por meio dos pilotis e o predomínio dos espaços abertos e da vegetação" (LEITÃO, 2009, p. 89).

As Superquadras residenciais, intercaladas pelas entrequadras (comércio local, recreio, equipamentos de uso comum) se sucedem, regular e linearmente dispostas ao longo dos $6 \mathrm{~km}$ de cada ramo do eixo arqueado (Eixo Rodoviário-Residencial). A escala definida por essa sequência entrosa-se com a escala monumental não apenas pelo gabarito das edificações como pela definição geométrica do território de cada quadra por meio da arborização densa da faixa verde que a delimita e lhe confere cunho de "pátio interno" urbano (GUIA DE BRASÍLIA, 2013)

Conforme cita Holston (1993, p.161):

\begin{abstract}
Os blocos de apartamentos de uma superquadra são todos iguais: a mesma fachada, a mesma altura, as mesmas facilidades, todos construídos sobre pilotis, todos dotados de garagem e construídos com o mesmo material, o que evita a odiosa diferenciação de classes sociais, isto é, todas as famílias vivem em comum, $o$ alto funcionário público, o médio e o pequeno. [...] e por causa de sua distribuição e inexistência de discriminação de classes sociais, os moradores de uma superquadra são forçados a viver como que no âmbito de uma grande família, em perfeita coexistência social, o que redunda em benefício das crianças que vivem, crescem, brincam e estudam num mesmo ambiente de franca camaradagem, amizade e saudável formação.
\end{abstract}

A escala gregária, prevista para o centro da cidade teve a intenção de criar um espaço urbano mais densamente utilizado e propício ao encontro. Esta escala surge, logicamente, em torno da interseção dos dois eixos (o Rodoviário e o Monumental): a Plataforma Rodoviária, elemento de vital importância na concepção da cidade e que se tornou, além do mais, o ponto de ligação de Brasília com as cidades satélites. No centro urbano, a densidade de ocupação se previu maior e os gabaritos mais altos, à exceção dos dois Setores de Diversões (GUIA DE BRASÍLIA, 2013).

As extensas áreas livres, a serem densamente arborizadas ou guardando a cobertura vegetal nativa, diretamente contígua a áreas edificadas, marcam a presença da escala bucólica. E a intervenção da escala bucólica no ritmo e na harmonia dos espaços urbanos se faz sentir na passagem, sem transição, do ocupado para o não ocupado. Em lugar de muralhas, a cidade se propôs delimitada por áreas livres arborizadas (GUIA DE BRASÍLIA, 2013). Santos (2008) informa que, como diretrizes gerais 
para a preservação do conjunto urbano como um todo, optou-se pela divisão do sítio tombado em quatro grandes áreas, relativas ao conceito de escala urbana, sendo feita uma subdivisão a partir de critérios específicos para cada uma dessas áreas. Dessa forma, como síntese dos preceitos que orientam a preservação, além das quatro escalas, pode-se relacionar:

- A percepção dos elementos arquitetônicos símbolos, representados pelas edificações referenciais ou o conjunto delas;

- Preservação do desenho urbano a partir de sua concepção original pelo cruzamento dos dois eixos em forma de cruz;

- Manutenção dos Eixos Rodoviário e Monumental como principais elementos estruturadores do sistema de circulação urbana;

- Manutenção de predominância dos espaços livres de edificações sobre os espaços construídos;

- Manutenção do espelho d'água do Lago Paranoá na cota de 1000 (mil), sendo vedada a modificação de sua orla por meio de aterros e cortes.

\section{Brasília x tombamento}

Em entrevista concedida para o jornal A Folha, o arquiteto Oscar Niemeyer, responsável pelos principais edifícios da capital, apresentou sua decepção com o tombamento de Brasília, pois, segundo ele, "as cidades sempre acabam sendo modificadas, queira ou não queira. Sempre aparece uma coisa nova que obriga a modificação" (MENCHEN, 2009).

Ainda segundo Niemeyer, percebe-se que o desenvolvimento de Brasília tem sofrido entraves graças ao tombamento, que tem causado também problemas nas Regiões Administrativas (RAs), que são classificadas pelo arquiteto como "grandes favelas esquecidas pelo governo” (MENCHEN, 2009). A sugestão de Niemeyer então, para diminuir a grande diferença entre ricos e pobres na capital é a descentralização de empregos e melhoria dos serviços básicos nas RAs (MENCHEN, 2009).

Rossetti (2012) ressalta que Brasília, embora seja a Capital Federal, apresenta características inerentes à dinâmica das cidades brasileiras decorrentes das próprias transformações econômicas, sociais, culturais e tecnológicas ocorridas nos últimos 50 anos. Por isso, não pode ser pensada apenas pelos instrumentos convencionais de preservação relativos a outras cidades históricas. Para essa autora, assim, a preservação de Brasília:

demanda uma visão mais abrangente que incluí a escala do planejamento urbano, extrapolando a dimensão da área tombada, considerando as áreas urbanizadas contíguas ao Plano Piloto, considerando ainda a dinâmica regional inerente a uma capital. Ou seja, o planejamento urbano do Distrito Federal tem implicações na preservação do Plano Piloto (ROSSETI, 2012).

A pressão sobre as áreas destinadas a espaços abertos é crescente, sendo estas, em alguns locais, ocupadas irregularmente com fins comerciais ou residenciais. Em virtude da pressão do setor imobiliário, que torna-se maior a cada dia, o projeto de cidade-parque vai sendo desfigurado, gerando situações como o caso do Lago Norte onde mais da metade da sua área é ocupada irregularmente (CORREIO BRAZILIENSE, 2011).

No ano de 2012, a UNESCO enviou uma missão à Brasília para avaliar o estado de conservação do sítio inscrito na Lista do Patrimônio Mundial. Foram identificados os principais pontos da cidade que necessitavam de cuidados urgentes, sendo que praticamente toda a cidade se enquadrou neste quesito:

Orla do Lago Paranoá: a missão da UNESCO identificou esta como sendo uma área crítica, onde há diversas construções irregulares, que desrespeitam os limites para espaços abertos e áreas verdes. No projeto inicial, a Orla do Lago Paranoá deveria ser aberta a toda a comunidade, excluindo apenas as áreas dos clubes, porém isso não pode ser visualizado em diversos trechos da Orla, onde mansões da classe alta tomam a localidade sem respeitar as normas fixadas em lei (UNESCO, 2012a).

Veículo Leve sobre Trilhos: O veículo leve sobre trilhos, uma alternativa para os trabalhadores se deslocarem com maior facilidade, para a UNESCO (2012a) tem como principal problema não ter sido realizado para este o estudo prévio de impacto ambiental. Uma medida proposta pelo relatório da UNESCO é o investimento em um plano diretor de Transporte Urbano, a partir das necessidades da população, visando a soluções em longo prazo.

Estádio Nacional de Brasília e Copa de 2014: também alvo de críticas. Para a mesma organização, as obras da Copa não foram bem planejadas, podendo causar sérios impactos ao patrimônio (UNESCO, 2012a).

Deterioração da Avenida W3: concebida para ser uma avenida de serviços, a W3 está em grave estado. A missão da UNESCO apontou as mudanças das casas ger- 
minadas que estão perdendo seu caráter residencial e a necessidade de controle de novas construções (UNESCO, 2012a).

Setor Noroeste e Vila Planalto: para manter o tradicional Plano Piloto, há a necessidade de se planejar com cuidado o setor Noroeste e a Vila Planalto, visto que sua expansão desordenada pode modificar o formato da cidade e seus arredores, porém o histórico de ocupação do Distrito Federal não tem respeitado esses limites (UNESCO, 2012a).

\section{Desenvolvimento das Regiões administrati-} vas: a principal meta é a descentralização dos empregos. Nesse ponto o relatório da UNESCO (2012a) é crítico: o problema com o transporte das RAs para o Plano Piloto ainda não foi resolvido, além das áreas de lazer que permaneceram apenas no projeto.

Altura das Edificações: no Decreto n 10829/87 está previsto para as áreas residenciais das superquadras numeradas de 102 a 116, de 202 a 216 e de 302 a 316, edificações de seis pavimentos, piso térreo em pilotis, e sem qualquer construção que não seja de acesso às residências e portarias. Porém, o que se percebe é outra configuração que se aproveita dos pontos não mencionados na legislação. Atualmente há a utilização das coberturas com caráter individual, além de diversos prédios cercarem o piso térreo, com intuito de aumentar a segurança dos moradores (UNESCO, 2012a).

Ao analisar os diversos pontos de conflito entre o relatório da UNESCO e a realidade da população envolvida, percebe-se uma necessidade urgente de intervenção na área. O próprio superintendente do IPHAN no ano de 2012, Alfredo Gastal, afirma:

Brasília não pode ser uma cidade congelada. A sobrevivência de Brasília hoje, com os três milhões que estão em volta dela, depende de descentralizar empregos, melhorar transporte de massa e a qualidade de vida nas cidades satélites (GLOBO, 2012).

Segundo Santos (2008), das quatro escalas urbanas estruturadoras da cidade e da Legislação de Tombamento, a bucólica, foi a que mais sofreu com os processos de ocupação e produção espacial posteriores à inauguração de Brasília, pois foram nos espaços constituinte desta que se encontraram os vazios passíveis de exploração pelo mercado imobiliário.

Assim, o Lago Paranoá, componente da escala bucólica, teve como característica uma conformação espacial diferente do restante do Plano Piloto. Sofreu, desde o início, inúmeros processos de ocupação não previstos na proposta original. O que tornou sua forma cada vez mais distante do pensado em 1957 e cada vez mais próxima da forma como rotineiramente as raridades paisagísticas são apropriadas nas demais cidades não planejadas.

Como forma de incentivar a ida dos funcionários públicos federais, originários do Rio de Janeiro para Brasília, uma série de equipamentos, já previstos, destinados ao lazer e ao esporte foram construídos às margens do Lago Paranoá, Clubes Sociais e Associações Esportivas. Essas ações somadas às doações de áreas localizadas às margens do Lago, feitas pela NOVACAP, auxiliaram no processo de descaracterização da orla do Paranoá, enquanto áreas de livre acesso à população de Brasília (SANTOS, 2008).

Esse autor, também informa que inúmeras foram as concessões feitas pelas sucessivas administrações de Brasília no tocante à ocupação da orla do Lago Paranoá, fazendo com que nos anos de 1980, este já se encontrasse quase todo inacessível ao público.

De acordo com Santos (2008), os documentos que tratam do tombamento de Brasília, quando abordam questões relativas à descaracterização das Escalas Gregária e Residencial - nas quais a Escala Bucólica ocupa as áreas intersticiais - relacionam os seguintes problemas:

- Privatização do espaço entre os pilotis, mediante a instalação de grades ou outro impedimento da livre circulação dos pedestres, bem com sua utilização para estacionamento;

- A permissão de construção de coberturas sobre o sexto andar, ou seja, a criação de um sétimo andar nos edifícios, por força da Lei Distrital $n^{\circ}$ 2.325/99;

— Os "puxadinhos" — a invasão de área pública por estabelecimentos comerciais nas quadras da Asa Sul e da Asa Norte;

- A invasão de áreas públicas nobres pelo comércio informal ou por estacionamentos;

- Na Avenida W3, o desrespeito às normas de gabarito;

- A utilização sem critérios de letreiros - painéis, faixas de propaganda e placas luminosas — responsáveis pela poluição visual;

- A descaracterização das residências das quadras 700, norte e sul;

Desconstituição das Unidades Vizinhanças, entre outras intervenções de igual gravidade. 
Santos (2008) também verificou que o pouco que restou das margens do Paranoá com possibilidade de livre acesso público, muitas vezes se mostra insuficiente para a construção dos equipamentos públicos voltados para a cultura e lazer. O que acaba por inviabilizar a efetivação da vocação do Lago Paranoá para as atividades de lazer, possíveis de serem realizadas pela população de Brasília com um todo.

Apesar da pouquíssima acessibilidade da Orla, a legislação do tombamento enfatiza as recomendações no tocante à conservação das características dessa porção da Escala Bucólica com as seguintes recomendações:

- Ampliar o leque de usos complementares, diversificando as atividades desenvolvidas;

- Não permitir o fechamento dos terrenos com muros ou alambrados altos;

- Estudar o reparcelamento tendo em vista a disponibilidade de áreas sem destinação;

- Com relação ao Jardim Zoológico, as características da área devem ser mantidas, com alterações que se fizerem necessárias ao seu funcionamento;

- Quanto ao acampamento da Telebrasília, estudar o reparcelamento da área, para o uso predominantemente residencial unifamiliar, com baixa densidade de ocupação, gabarito térreo, estabelecendo uma poligonal delimitadora;

- E, função dos reparcelamentos anteriores referidos, realizar readequação do sistema viário, preservando as vias principais existentes;

- Promover estudos que possibilitem a criação de um polo turístico-cultural, que integre as áreas do Brasília Palace Hotel, Museu de Arte de Brasília e Concha Acústica;

- No caso da construção de novas pontes ligando a cidade aos setores Lago Sul e Norte, minimizar o impacto da conexão com o sistema viário da área $\mathrm{A}$;

- Desenvolver estudos sobre a destinação do acampamento Saturnino de Brito (SANTOS, 2008, p. 147).

De acordo com Paviani (2005), no projeto inicial de Lúcio Costa, Brasília estava destinada a ser uma cidade fechada com população de até 600 mil habitantes, porém, seu rápido desenvolvimento fez surgir novos bairros que foram implantados distantes do Plano Piloto para abrigar operários provenientes dos canteiros de obras da Capital e da grande leva de imigrantes que afluía para a nova cidade.

Com a impossibilidade de aumento populacional do centro da capital, pois as escalas definidas no projeto urbano da cidade deveriam ser seguidas, o excedente foi sendo transferido para as então denominadas "cidades-satélites" próximas, reservando o centro, o Plano Piloto, para a população ocupante dos cargos públicos administrativos, destino oficial da nova Capital. Tal medida, deu início assim, à desigualdade social e segregação socioespacial no território do DF.

Brasília, Gama, Taguatinga, Brazlândia, Sobradinho, Planaltina e Paranoá foram as primeiras cidades criadas em dezembro de 1964, conforme a Codeplan (apud BOECHAT, 2011). No relatório, Brasília Revisitada (1985/1987), Lúcio Costa definiu que a população da época não poderia ter uma grande expansão, já que Brasília não teria capacidade de abrigar tantas pessoas. Para ele, Brasília não foi concebida para ser uma "metrópole".

Hoje, com mais de 30 Regiões Administrativas, sendo considerada uma cidade polinucleada, a malha urbana de Brasília cresce rapidamente para atender a grande população que faz uso de boa parte das RA's apenas para seu descanso, pois o centro mantém a maior porcentagem dos empregos da capital, 76\% (ARAGÃO, 2011).

Portanto, de uma forma geral, percebe-se que muito da atual cidade se difere do plano inicial. $\mathrm{Na}$ atualidade então, a população se vê cada vez mais interessada em melhorias na qualidade de vida, por meio da geração de empregos e investimento nos equipamentos públicos, mas, da forma como tem-se dado a política de preservação no Distrito Federal, muitas dessas necessidades urgentes têm sido colocadas de lado.

\section{Considerações finais}

O presente trabalho procurou analisar a configuração inicial proposta no Plano Piloto para Brasília e as suas modificações ocasionadas pelo crescimento desordenado ou falta de planejamento adequado ao longo dos anos de criação e desenvolvimento da cidade.

Apesar disso, constata-se que a concepção urbanística inicial ainda se mantém em muitos pontos, seguindo as quatro escalas propostas por Lúcio Costa, sendo que a escala bucólica foi a que se encontra em maior estado de degradação na atualidade.

Como demonstra o relatório da UNESCO (2012a), há falta de cooperação entre governo federal por 
meio do IPHAN e Governo do Distrito Federal no que tange à preservação de Brasília, sendo este um dos fatores responsáveis pela maioria dos problemas na capital.

Outro ponto de importância mencionado por Oscar Niemeyer (A FOLHA, 2009) é a degradação das Regiões Administrativas. Segundo ele, como a classe alta, principalmente formada por servidores públicos, está concentrada no centro do Plano Piloto, os principais serviços também estão fixados neste, fazendo com que a maior parte da população de outras regiões acabe sendo esquecida pelo governo.

Percebe-se assim, a necessidade de uma intervenção a longo prazo que possa: requalificar as áreas mais críticas como a avenida W3; reestruturar o uso indevido do solo, como na orla do Lago Paranoá e nas Áreas Residenciais; trazer melhorias (relacionadas a infraestrutura básica e oferta de empregos) para a região metropolitana de Brasília, tentando desafogar o centro do Plano Piloto que ainda é o principal destino da maioria dos trabalhadores da região.

\section{Referências}

ARAGÃO, Juliano Pestana de. Do rodoviarismo a uma cidade mais humana: o coletivo e o não motorizado nos deslocamentos urbano de Brasília. 2011. 60 f. Dissertação (Mestrado). Departamento de Geografia da Universidade de Brasília. Instituto de Ciências Humana, Brasília, 2011.

BOECHAT, Juliana. De cidade-satélite a bairro. 19/01/2011. Disponível em: <http://www.unb.br/noticias/unbagencia/cpmod.php?id=82606>. Acesso em: 20 jun. 2013.

BORGES, Marco Antônio. O tombamento como instrumentos jurídicos para a proteção do patrimônio cultural. Belo Horizonte. 2005. Disponível em: <http://www.planalto.gov.br/ccivil_03/revista/rev_73/artigos/MarcoAntonio_rev73.htm>. Acesso em 09 jun. 2013.

BRASIL. Constituição (1891). Constituição da República dos Estados Unidos do Brasil. Disponível em: <http:// www.planalto.gov.br/ccivil_03/constituicao/constituicao91.htm>. Acesso em: 19 jun. 2013.

BRASIL. Constituição (1988). Constituição da República Federativa do Brasil. Brasília, DF. Disponível em: <http:// www.planalto.gov.br/ccivil_03/constituicao/constituicao. htm>. Acesso em: 13 jun. 2013.

BRASIL. Decreto $n^{\circ} 10.829$, de 14 de outubro de 1987. Disponível em: <http://www.brasiliapatrimoniodahumanidade. df.gov.br/legislacao/DISTRITAL/2_DECRETO_10.829-87/ Dec_10829-87_Preservacao_da_concepcao_urbanistica_ de_Brasilia.pdf $>$. Acesso em: 14 fev. 2013.
BRASIL. Decreto-Lei $n^{\circ}$ 25, de 30 de novembro de 1937. Organiza a proteção do patrimônio histórico e artístico nacional. Disponível em: <http://www.planalto.gov.br/ ccivil_03/decreto-lei/del0025.htm>. Acesso em: $20 \mathrm{fev}$. 2013.

CATALDO, Beth; RAMOS, Graça (Org.). Brasília aos 50 anos: que cidade é essa? Brasília: Tema, 2010.

CORREIO BRAZILIENSE. Mais da metade do Lago Norte está ocupada irregularmente. Brasília, 2011.

COSTA, Lúcio. O Relatório do Plano de Piloto de Brasília. Disponível em: <http://brasiliapoetica.blog.br/site/ media/relatorio_plano_piloto_de_brasilia_web2.pdf $>$. Acesso em: 13 jul. 2013.

COSTA, Lucio. Brasília revisitada 1985/1987: complementação, preservação, adensamento e expansão urbana. Projeto, São Paulo, n. 100, jun. 1987.

GLOBO. Iphan diz que relatório da Unesco sobre Brasília teve 'tom imoderado'. 06/06/2012. Disponível em: <http:// g1.globo.com/distrito-federal/noticia/2012/06/iphan-diZ-que-relatorio-da-unesco-sobre-brasilia-teve-tom-imoderado.html>. Acesso em: jun. 2013.

GUIA DE BRASÍLIA. Histórico. Disponível em: <http:// www.guiadebrasilia.com.br/historico/historico.htm $>$. Acesso em: 05 jun. 2013.

HOLSTON, James. Cidade modernista: uma crítica de Brasília e sua utopia. São Paulo: Companhia de Letras, 1993.

INSTITUTO DO PATRIMÔNIO HISTÓRICO ARTISTICO NACIONAL - IPHAN. Tombamento. Disponível em: <http://portal.iphan.gov.br/portal/montarPaginaSecao.do? $\mathrm{id}=17738 \&$ sigla $=$ Institucional\&retorno=paginaInstitucional>. Acesso em: 19 ago. 2014.

JUCÁ, Jane Monte. Princípios da cidade-parque: categoria urbana concebida no Plano Piloto de Brasília. VITRUVIUS. Brasília, 10 dez. 2009. Disponível em: $<$ http://www.vitruvius.com.br/revistas/read/minhacidade/10.113/1824>. Acesso em: 13 abr. 2013.

LEITÃO, Francisco (Org.). Brasília 1960-2010: passado, presente e futuro. Brasília: Secretaria de Estado de Desenvolvimento Urbano e Meio Ambiente (SEDUMA), 2009.

MENCHEN, Denise. Entrevista Oscar Niemeyer. Tombamento de Brasília é uma besteira. Folha de São Paulo. 02 de fevereiro de 2009. Disponível em:<http://www1.folha. uol.com.br/fsp/brasil/fc0202200913.htm>. Acesso em: 13 jun. 2014. 
PAVIANI, Aldo. Brasília, capital complexa. Correio Braziliense, Brasília, abr. 2005. Caderno Opiniões, p. 19.

PESSÔA, José Simões de Belmont. Brasília e o tombamento de uma ideia. Escola de Arquitetura e Urbanismo-UFF, s.d.

PREFEITURA DA HIGS 706. Plano de Preservação do Conjunto Urbanístico de Brasília. 9 de maio de 2010. Disponível em: <http://higs706.blogspot.com.br/2010/05/ plano-de-preservacao-do-conjunto_09.html>. Acesso em: 19 abr. 2013.

ROSSETTI, Eduardo Pierrotti. Brasília-patrimônio: cidade e arquitetura moderna encarando o presente. Outubro/2011. Disponível em: <http://www.vitruvius.com.br/ revistas/read/arquitextos/13.149/4547>. Acesso em: 20 jul. 2014.

SANTOS, Marcos Antônio dos. Brasília, o Lago Paranoá e o Tombamento: natureza e especulação na Cidade Modernista. São Carlos, 2008. Dissertação (Mestrado-Programa de Pós-Graduação em Arquitetura e Urbanismo e Área de Concentração em Teoria e História da Arquitetura e Urbanismo) EESC/USP. São Carlos, 2008.

SECRETARIA DE ESTADO DA CULTURA (DF). Tombamento. Disponível em: <http://www.brasiliapatrimoniodahumanidade.df.gov.br/index.php?option $=\mathrm{com}_{-}$ content\&view $=$ article\&id=51\&Itemid=19>. Acesso em: 20 abr. 2013.

SECRETARIA DE ESTADO DA CULTURA DO PARANÁ. Coordenação do Patrimônio Cultural. Tombamento. Conceitos. Disponível em: <http://www.patrimoniocultural.pr.gov.br/modules/conteudo/conteudo.php?conteu$\mathrm{do}=4>$. Acesso em: 19 abr. 2013.

SECRETARIA DE HABITAÇÃO, REGULARIZAÇÃO E DESENVOLVIMENTO URBANO (SEDHAB - DF). Ano de Valorização do Patrimônio Cultural da Humanidade. Brasília, 2012. Disponível em: <http://www.brasili apatrimoniodahumanidade.df.gov.br/index.php?option $=\mathrm{com}_{-}$ content\&view $=$ article\&id $=1 \&$ Itemid $=2>$. Acesso em: 25 abr. 2013.
SECRETARIA DE ESTADO DE PLANEJAMENTO E ORÇAMENTO DO DF - SEPLAN. Capital de todos os brasileiros foi o primeiro monumento moderno incluído na lista de bens materiais da humanidade. 07 de dezembro de 2012. Disponível em: <http://www.seplan.df.gov.br/ noticias/item/2082-bras\%C3\%ADlia-comemora-25-anos-como-patrim\%C3\%B4nio-cultural-da-humanidade. html>. Acesso em: 20 ago. 2014.

TAVARES, Jeferson. O concurso para a Capital Federal. 192 ed. março/2010b. Disponível em: <http://au.pini. com.br/arquitetura-urbanismo/192/intersecao-brasilia-50-anos-o-concurso-para-a-capital-163574-1.aspx $>$. Acesso em: 13 jul. 2014.

TAVARES, Jeferson. O concurso para o Plano Piloto de Brasília: território e infraestrutura. In: I ENCONTRO NACIONAL DA ASSOCIAÇÃO NACIONAL DE PESQUISA E PÓS-GRADUAÇÃ̃O EM ARQUITETURA E URBANISMO. Rio de Janeiro, 29 de novembro a 03 de dezembro de 2010a. Disponível em: <http://www.anparq. org.br/dvd-enanparq/simposios/158/158-721-1-SP.pdf > . Acesso em: 14 jul. 2014.

UNESCO. Convenção para a Proteção do Patrimônio Mundial, Cultural e Natural. 1972. Disponível em: $<$ http://whc.unesco.org/archive/convention-pt.pdf $>$. Acesso em: 20 abr. 2013a.

UNESCO. Convention Concerning the Protection of the World Cultural and Natural Heritage. 2012. Disponível em: <http://whc.unesco.org/archive/convention-pt.pdf $>$. Acesso em: jul. 2013.

UNESCO. Patrimônio Cultural no Brasil. Disponível em: $<$ http://www.unesco.org/new/pt/brasilia/culture/world-heritage/cultural heritage/\#c154836>. Acesso em: 20 maio 2013b.

VEJA. Brasília 50 anos: o nascimento de uma nação. Disponível em: <http://veja.abril.com.br/especiais/brasilia/ index.html>. Acesso em: 25 maio 2013. 